\title{
FREQUENCY OF PRE-ECLAMPSIA IN PATIENTS WITH ABNORMAL UTERINE ARTERY DOPPLER AT TWENTY TWO TO TWENTY FOUR WEEKS OF GESTATION.
}

\footnotetext{
1. FCPS (Gyne \& Obs)

Assistant Professor (Gyne \& Obs.)

Nishtar Medical University, Multan, Pakistan.

2. FCPS (Gyne \& Obs)

Consultant Gynecologist

Indus Hospital, Muzaffargarh, Pakistan.

3. FCPS (Gyne \& Obs)

Assistant Professor (Gyne \& Obs.)

Nishtar Medical University, Multan, Pakistan.

4. Post-graduate Trainee (Gyne \& Obs.)

Nishtar Medical University, Multan, Pakistan.

5. FCPS (Gyne \& Obs)

Assistant Professor (Gyne \& Obs.) Nishtar Medical University, Multan, Pakistan.
}

Correspondence Address:

Dr. Shagufta Tabassum

Department of Gyne \& Obs

Nishtar Medical University, Multan,

Pakistan.

dr.shaguftatabassum@hotmail.com

Article received on:

29/11/2019

Accepted for publication:

$10 / 02 / 2020$

\section{Shagufta Tabassum ${ }^{1}$, Samina Mumtaz ${ }^{2}$, Asiya Fayyaz ${ }^{3}$, Faiza Suman ${ }^{4}$, Saima Yasmin Qadir ${ }^{5}$}

ABSTRACT... Objectives: To determine the frequency of pre-eclampsia among pregnant ladies with abnormal uterine artery Doppler at 22- 24 weeks of gestation at a tertiary care hospital. Study Design: Cross sectional study. Setting: Department of Obstetrics and Gynecology, Nishtar Medical University / Hospital Multan. Period: All the women $(n=160)$ with abnormal uterine artery Doppler from 01-07-2018 to 30-06-2019 were included. Material \& Methods: The pulsatility index $(\mathrm{PI})$ of uterine artery Doppler was taken by taking average of 3 consecutive waveforms to determine the abnormal uterine artery Doppler. These study cases were followed till delivery to document pre-eclampsia. Results: Of these 160 study cases, 89 (55.6\%) had gestational age up to 23 weeks while $71(44.4 \%)$ had gestational age more than 23 weeks having mean age of $25.44 \pm 4.77$ years. Of these 160 pregnant ladies with abnormal uterine artery Doppler, $72(45.0 \%)$ were resident of rural areas and $88(55.0 \%)$ were resident of urban areas and family history of pre-eclampsia was $42(26.3 \%)$. Previous history of pre-eclampsia was noted in $41(25.6 \%)$. Mean parity was $2.24 \pm 1.06$ and $113(70.6 \%)$ had parity up to 3 . Mean gravidity of our study cases was $3.87 \pm 1.16$ and $89(55.6 \%)$ had gravidity up to 4 . Obesity was present in $30(18.8 \%)$ having mean body mass index $25.23 \pm 1.92 \mathrm{~kg} / \mathrm{m}^{2}$. Mean interpregnancy interval was $14.19 \pm 6.82$ months and $83(51.9 \%)$ had interpregnancy interval more than 1 year and pre-eclampsia was noted in $125(78.1 \%)$. Conclusion: Very high frequency of preeclampsia was noted in our study in pregnant women presenting with abnormal uterine artery Doppler at $22-24$ weeks of gestation. Pre-eclampsia was significantly associated with age, family history of pre-eclampsia, previous history of pre-eclampsia and interpregnancy interval.

Key words: $\quad$ Abnormal Uterine Artery Doppler, Frequency, Pre-eclampsia.

Article Citation: Tabassum S, Mumtaz S, Fayyaz A, Suman F, Qadir SY. Frequency of pre-eclampsia in patients with abnormal uterine artery Doppler at twenty two to twenty four weeks of gestation. Professional Med J 2020; 27(6):1280-1284. DOI: 10.29309/TPMJ/2020.27.06.4379

\section{INTRODUCTION}

Pre-eclampsia complicates around $5-7 \%$ of total pregnancies all over the world and is specified with placental and maternal vascular dysfunction which leads to adverse perinatal outcomes e.g. hypertension, placental abruption, intrauterine growth restriction, eclampsia and even fetomaternal mortalities. ${ }^{1,2}$ It is regarded as one of the leading causes of maternal and neonatal morbidities and mortalities. ${ }^{3,4}$ Additionally preeclamptic patients are always at increased risk of development of cardiovascular diseases in later ages of their life. Various risk factors implicated in the development of pre-eclampsia may include; obesity, extreme maternal age (less than 15 years and more than 35 years), diabetes, twin pregnancies, chronic renal diseases and African
American race..$^{5-7}$

Recent estimates of World Health Organization (WHO) have reported worldwide mortalities associated with pre-eclampsia as over 100000 every year, particularly in developing countries. ${ }^{8}$ These estimates point towards precise prediction of preeclampsia to improve services delivery of antenatal surveillance and therapy, with an objective to improve pregnancy outcomes. Under these circumstances, potential target is believed to be associated with assessment of uteroplacental circulation in high risk population such as obese, diabetic, positive family history, extreme maternal ages and previous history. Assessment of uteroplacental circulation is usually achieved by Doppler Ultrasonography 
of uterine arteries. ${ }^{9}$ Traditionally, pre-eclampsia is believed to be caused by certain underlying conditions such as; abnormalities in placental formation, by abnormal trophoblast patterns of spiral arteries and enhanced resistance observed in the uteroplacental circulation. ${ }^{10}$

Pregnancies associated with higher diastolic blood flow velocity and early diastolic notch up to 22 weeks of pregnancy have been found to result in normal term deliveries whereas those pregnancies which exhibit increased resistance waveforms having early diastolic notch have been reported to be destined to result in increased rates of preterm deliveries, placental abruption and IUGR due to pre-eclampsia. ${ }^{11}$ Barati et al $^{12}$ reported as high as $88.2 \%$ pre-eclampsia in patients with abnormal uterine artery Doppler.

This study was planned to document frequency of pre-eclampsia in patients with abnormal uterine artery Doppler in our local population, owing to genetic diversity and life style modifications as it was noted that there is no published study available in our local database of Pakistan, though we treat such patients with abnormal uterine artery Doppler frequently in our routine duties.

\section{MATERIAL \& METHODS}

This cross-sectional study was done at Department of Obstetrics and Gynecology, Nishtar Hospital Multan. The study extended from 01-07-2018 to 30-06-2019. All the women, whether primigravida or multigravida, having age ranging from 20-40 years, with abnormal uterine artery Doppler at 22-24 weeks of gestation (assessed on LMP) were recruited. Sample size was $(n=160)$, calculated by formula: $n=z^{2} p q /$ $d^{2}$, Where $z=1.96, p=88.2 \%{ }^{12}, d=5 \%$. The mean pulsatility index (PI) from the left and right uterine arteries was calculated at 22-24 weeks of gestation using Doppler ultrasonography and mean PI more than 1.45, the flow velocity waveform and presence of bilateral early diastolic notches was considered abnormal.

Twin pregnancy, patients of renal disease (having raised serum creatinine level $>2 \mathrm{mg} /$ dl), cardiovascular disease (known patients with valvular heart disease, congenital heart diseases, IHD which was confirmed from patient record file), liver disease (known cases of CLD diagnosed on ultrasonography and laboratory report), diabetes (known diabetic patients who are taking hypoglycemic drugs), diagnosed cases of thyroid dysfunction (showing derangement in any of T3, T4 and TSH) and patients having malignancies (on histopathology report) were excluded from our study. Detailed history (like age, parity, gestational age, residential status and obesity) and physical examination was conducted. These study cases were followed till delivery to document pre-eclampsia. Data entry and analysis was done by SPSS Version 20. Frequencies and percentages were tabulated for categorical variables like residential status, family history of pre-eclampsia, parity, gravidity, obesity, previous history of preeclampsia and age groups. Effect modifiers like age, residential status, family history of pre-eclampsia, parity, gravidity, Obesity (BMI $\left.>27.5 \mathrm{~kg} / \mathrm{m}^{2}\right)$, interpregnancy interval and gestational age were controlled by stratification of data along with chi-square test at $95 \% \mathrm{Cl}$.

\section{RESULTS}

A total of 160 patients with abnormal uterine artery Doppler were taken, 89 (55.6 \%) had gestational age up to 23 weeks while 71 (44.4 $\%)$ had gestational age more than 23 weeks. Mean age was $25.44 \pm 4.77$ years with 20-38 years range and 137 (85.6\%) were aged up to 30 years. Of these 160 pregnant ladies with abnormal uterine artery Doppler, 72 (45.0\%) were resident of rural areas and 88 (55.0\%) were resident of urban areas. Family history of pre-eclampsia was 42 (26.3\%). Previous history of pre-eclampsia was noted in 41 (25.6\%). Mean parity of our study cases was $2.24 \pm 1.06$ and $113(70.6 \%)$ had parity up to 3 . Mean gravidity of our study cases $3.87 \pm 1.16$ and $89(55.6 \%)$ had gravidity up to 4 . Obesity was present in 30 (18.8 $\%)$ having mean body mass index $25.23 \pm 1.92$ $\mathrm{kg} / \mathrm{m}^{2}$. Mean interpregnancy interval was $14.19 \pm$ 6.82 months and $83(51.9 \%)$ had interpregnancy interval more than 1 year. Mean gestational age at the development of pre-eclampsia was $33.12 \pm$ 2.54 weeks and pre-eclampsia was noted in 125 (78.1\%) of our study cases. Pre-eclampsia was 
stratified with regards to gestational age, age, residential status, obesity, parity, gravidity, family history, previous history and interpregnancy interval.

\begin{tabular}{|c|c|c|c|c|}
\hline \multirow{2}{*}{\multicolumn{2}{|c|}{ Confounding Variables }} & \multicolumn{2}{|c|}{ Preeclampsia } & \multirow{4}{*}{$\begin{array}{c}\text { P-Value } \\
0.701\end{array}$} \\
\hline & & \multirow{2}{*}{$\begin{array}{c}\text { Yes }(n=125) \\
71\end{array}$} & \multirow{2}{*}{$\begin{array}{c}\text { No }(n=35) \\
18\end{array}$} & \\
\hline Gestational Age & Up to $23(n=89)$ & & & \\
\hline (In weeks) & More than $23(n=71)$ & 54 & 17 & \\
\hline \multirow{2}{*}{$\begin{array}{l}\text { Age groups } \\
\text { (In Years) }\end{array}$} & Up to $30(n=137)$ & 102 & 35 & \multirow{2}{*}{0.005} \\
\hline & More than $30(n=23)$ & 23 & 00 & \\
\hline \multirow{2}{*}{ Residential status } & Rural $(n=72)$ & 49 & 23 & \multirow{2}{*}{0.007} \\
\hline & Urban $(n=88)$ & 76 & 12 & \\
\hline \multirow{2}{*}{ Family History } & Yes $(n=42)$ & 42 & 00 & \multirow{2}{*}{0.001} \\
\hline & No $(n=118)$ & 83 & 35 & \\
\hline \multirow{2}{*}{ Previous history } & Yes $(n=41)$ & 41 & 00 & \multirow{2}{*}{0.000} \\
\hline & No $(n=119)$ & 84 & 35 & \\
\hline \multirow{2}{*}{ Obesity } & Yes $(n=30)$ & 24 & 06 & \multirow{2}{*}{1.000} \\
\hline & No $(n=130)$ & 101 & 29 & \\
\hline \multirow{2}{*}{ Parity } & Up to $3(n=113)$ & 84 & 29 & \multirow{2}{*}{0.093} \\
\hline & More than $3(n=47)$ & 41 & 06 & \\
\hline \multirow{2}{*}{$\begin{array}{l}\text { Short Interpregnancy } \\
\text { interval }\end{array}$} & Up to $12(n=77)$ & 53 & 24 & \multirow{2}{*}{0.007} \\
\hline & More than $12(n=83)$ & 72 & 11 & \\
\hline
\end{tabular}

\section{DISCUSSION}

Abnormal trophoblastic distribution of the spiral arteries is linked with increased risks associated with the higher proportions of pre-eclampsia, Intrauterine growth restriction (IUGR) and various other adverse perinatal outcomes. ${ }^{13-15}$ Globally, uterine artery Doppler has gained popularity as a screening test in middle stages of pregnancy. ${ }^{14}$ In our study, uterine artery Doppler was planned in 22-24 weeks of pregnancies which is contrary to many other studies who conducted it in the first trimester and early second trimester based upon hypothesis that this timing was unlikely to influence fetal growth and well - being.

Of these 160 study cases, 89 (55.6\%) had gestational age up to 23 weeks patients while 71 $(44.4 \%)$ had gestational age more than 23 weeks. Mean age was $25.44 \pm 4.77$ years ranging $20-38$ years and 137 (85.6\%) were aged up to 30 years. Ebrashy et $\mathrm{al}^{16}$ has reported mean age as $28.5 \pm$ 5.9 years. Schwarzman et $\mathrm{al}^{17}$ has also reported mean age as $27.30 \pm 6.44$ years while Talari et $\mathrm{al}^{18}$ has reported it to be $27.8 \pm 4.5$ years.
Family History of pre-eclampsia was noted in 42 (26.3\%) of our study cases. Previous history of pre-eclampsia was noted in 41 (25.6\%). Ebrashy et $\mathrm{al}^{16}$ has also reported $28.4 \%$ previous history of pre-eclampsia while $20.4 \%$ family history of preeclampsia; close to our results. Talari et al ${ }^{18}$ has also reported similar results.

Mean parity of our study cases was $2.24 \pm$ 1.06 and $113(70.6 \%)$ had parity up to 3 . Mean gravidity of our study cases $3.87 \pm 1.16$ and 89 $(55.6 \%)$ had gravidity up to 4 . Schwarzman et al ${ }^{17}$ has also reported $2.76 \pm 2.33$ mean parity while mean gravidity was $3.32 \pm 2.84$. Talari et $\mathrm{al}^{18}$ has also reported that $37.5 \%$ patients with abnormal uterine artery Doppler had parity equal/more than 3.

Obesity was present in 30 (18.8\%) having mean body mass index $25.23 \pm 1.92 \mathrm{~kg} / \mathrm{m}^{2}$ which is quite close to that reported by Talari et al ${ }^{18}$ (25.1 $\pm 3.2 \mathrm{~kg} / \mathrm{m}^{2}$ mean BMI.)

Mean gestational age at the development of preeclampsia was $33.12 \pm 2.54$ weeks. Barati et $\mathrm{al}^{12}$ 
has also reported that $17 \%$ patients developed preeclampsia before 32 weeks of gestation.

Pre-eclampsia was noted in 125 (78.1\%) while Verma et $\mathrm{al}^{19}$ has reported $41 \%$ preeclampsia which is quite lower than our study results. Barati et $\mathrm{al}^{12}$ has reported $88.2 \%$ preeclampsia, close to our study results.

\section{CONCLUSION}

Very high frequency of pre-eclampsia was noted in our study in pregnant women presenting with abnormal uterine artery Doppler at $22-24$ weeks of gestation. Pre-eclampsia was significantly associated with age, family history of preeclampsia, previous history of pre-eclampsia and interpregnancy interval.

Copyright@ 10 Feb, 2020.

\section{REFERENCES}

1. Phalak $P$, Tilak M. Study of lipid profile in pre -eclampsia. Indian J Basic Applied Med Res. 2012; 5(2):405-9.

2. Richards $D^{1}{ }^{1}$, Lindow SW, Carrara $H$, Knight R, Haswell SJ, Van der Spuy ZM. A comparison of maternal calcium and magnesium levels in pre-eclamptic and normotensive pregnancies: An observational casecontrol study. BJOG. 2014 Feb; 121(3):327-36.

3. Jeyabalan A. Epidemiology of preeclampsia: Impact of obesity. Nutr Rev. 2013; 71:18-25.

4. Tabesh M, Salehi-Abargouei A, Tabesh M, Esmaillzadeh A. Maternal vitamin D status and risk of preeclampsia: A systematic review and meta-analysis. J Clin Endocrinol Metab. 2013; 98(8):3165-73.

5. Abalos E, Cuesta C, Carroli G, Qureshi Z, Widmer $\mathrm{M}$, Vogel JP, et al. Pre-eclampsia, eclampsia and adverse maternal and perinatal outcomes: A secondary analysis of the World Health Organization Multicountry Survey on Maternal and Newborn Health. BJOG. 2014; 121:14-24.

6. Hutcheon JA, Lisonkova S, Joseph KS. Epidemiology of pre-eclampsia and the other hypertensive disorders of pregnancy. Best Pract Res Clin Obstet Gynaecol. 2011; 25(4):391-403.

7. Cetin I, Berti C, Calabrese S. Role of micronutrients in the periconceptional period. Hum Reprod Update. 2010; 16(1):80-95.
8. Jesmin S, Jahan S, Khan MI, Sultana N, Jerin J, Habib $\mathrm{SH}$, et al. The incidence, predisposing factors, complications and outcome of preeclampsia in diabetic pregnancy. Birdem Med J. 2012; 1(1):10-4.

9. Roberge S, Giguere Y, Villa P, Nicolaides K, Vainio $\mathrm{M}$, Forest JC, et al. Early administration of lowdose aspirin for the prevention of severe and mild preeclampsia: A systematic review and metaanalysis. Am J Perinatol. 2012; 29(7):551-6.

10. Talari $\mathrm{H}^{1}$, Mesdaghinia $\mathrm{E}^{2}$, Abedzadeh Kalahroudi $\mathrm{M}^{3}$. Aspirin and preeclampsia prevention in patients with abnormal uterine artery blood flow. Iran Red Crescent Med J. 2014 Aug; 16(8):e17175. doi: 10.5812/ ircmj. 17175.

11. Ghi T, Youssef A, Piva M, Contro E, Segata M, Guasina $F$, et al. The prognostic role of uterine artery Doppler studies in patients with late - onset pre-eclampsia. (e1-5).Am J Obstet Gynecol. 2009; 201 (1):36.e1-5.

12. Barati $M$, Shahbazian $N$, Masihi S. Diagnostic evaluation of uterine artery Doppler sonography for the prediction of adverse pregnancy outcomes. $J$ Res Med Sci. 2014 Jun; 19(6):515-19.

13. Shand AW ${ }^{1}$, Nassar N, Von Dadelszen $P$, Innis SM, Green TJ. Maternal vitamin D status in pregnancy and adverse pregnancy outcomes in a group at high risk for pre-eclampsia. BJOG. 2010; 117:1593-8.

14. Vadillo-Ortega $\mathrm{F}^{1}$, Perichart-Perera $\mathrm{O}$, Espino $\mathrm{S}$, AvilaVergara MA, Ibarra I, Ahued R, et al. Effect of supplementation during pregnancy with L-arginine and antioxidant vitamins in medical food on preeclampsia in high risk population: randomised controlled trial. BMJ. 2011; 342:d2901.

15. Kasawara $\mathrm{KT}^{1}$, do Nascimento $\mathrm{SL}$, Costa $\mathrm{ML}$, Surita FG, e Silva JL. Exercise and physical activity in the prevention of pre-eclampsia: Systematic review. Acta Obstet Gynecol Scand. 2012; 91:1147-57.

16. Ebrashy $A^{1}$, Ibrahim $M$, Marzook $A$, Yousef D. Usefulness of aspirin therapy in high-risk pregnant women with abnormal uterine artery Doppler ultrasound at 14-16 weeks pregnancy: Randomized controlled clinical trial. Croat Med J. 2005 Oct; 46(5):826-31.

17. Shwarzman $\mathrm{P}^{1}$, Waintraub AY, Frieger $\mathrm{M}$, Bashiri A, Mazor $M$, Hershkovitz R. Third-trimester abnormal uterine artery Doppler findings are associated with adverse pregnancy outcomes. J Ultrasound Med. 2013 Dec; 32(12):2107-13. doi: 10.7863/ultra.32.12.2107. 
18. Talari $\mathrm{H}^{1}$, Mesdaghinia $\mathrm{E}^{2}$, Abedzadeh Kalahroudi $\mathrm{M}^{3}$. Aspirin and preeclampsia prevention in patients with abnormal uterine artery blood flow. Iran Red Crescent Med J. 2014 Aug; 16(8):e17175. doi: 10.5812/ ircmj.17175. Epub 2014 Aug 5.
19. Verma $D^{1}$, Gupta $S^{1}$. Prediction of adverse pregnancy outcomes using uterine artery Doppler imaging at 2224 weeks of pregnancy: A North Indian experience. Turk J Obstet Gynecol. 2016 Jun; 13(2):80-84.

\begin{tabular}{|c|l|l|}
\hline \multicolumn{3}{|c|}{ AUTHORSHIP AND CONTRIBUTION DECLARATION } \\
\hline Sr. \# & \multicolumn{1}{|c|}{ Author(s) Full Name } & \multicolumn{1}{c|}{ Contribution to the paper } \\
\hline 1 & Shagufta Tabassum & $\begin{array}{l}\text { Data collection, Study design, } \\
\text { Interpretation, Principal } \\
\text { investigator, Final reading. } \\
\text { Data collection, Study design, } \\
\text { Interpretation. } \\
\text { Study collection, Study design, } \\
\text { Interpretation, Final reading. } \\
\text { Data collection, Study design, } \\
\text { Interpretation, Final reading. } \\
\text { Interpretation, Final reading. }\end{array}$ \\
\hline 5 & Asiya Fayyaz & Faiza Suman \\
\hline 5 & Saima Yasmin Qadir & \\
\hline
\end{tabular}

